\title{
Phasic Dopamine Release Magnitude Tracks Individual Differences in Sensitization of Locomotor Response following a History of Nicotine Exposure
}

Running Title: Dopamine Dynamics Following Repeated Nicotine

Ashley M. Fennell Ph.D.*, Elizabeth G. Pitts Ph.D.*, Lacey L. Sexton, and Mark J. Ferris Ph.D.

Department of Physiology and Pharmacology, Wake Forest School of Medicine, WinstonSalem, North Carolina 27157.

*These authors contributed equally to this work.

Corresponding Author:

Mark J. Ferris, PhD

Wake Forest School of Medicine

Department of Physiology and Pharmacology

1 Medical Center Blvd.

Winston-Salem, NC 27157

mferris@wakehealth.edu

Key words (8): drug addiction, nicotine, nucleus accumbens, striatum, dopamine, voltammetry, acetylcholine, nicotinic acetylcholine receptors

Word count: abstract (200); Article Body (4182)

\# of Tables: 0

\# of Figures: 4

\# of Supplemental Information: 0 


\section{Abstract}

Smoking remains the primary cause of preventable death in the United States and smoking related illness costs more than $\$ 300$ billion annually. Nicotine (the primary reinforcer in cigarettes) causes changes in behavior and neurochemistry that lead to increased probability of relapse. Given the role of mesolimbic dopamine projections in motivation, substance use disorder, and drug relapse, we examined the effect of repeated nicotine on rapid dopamine signals in the nucleus accumbens (NAc) of rats. Adult, male Sprague-Dawley rats were exposed to nicotine $(0.2$ or $0.4 \mathrm{mg} / \mathrm{kg}$, subcutaneous) once daily for 7 days. On day 8 , dopamine release and uptake dynamics, and their modulation by nicotinic receptor agonists and antagonists, were assessed using fast scan cyclic voltammetry in the NAc core. Nicotine exposure decreased electricallystimulated dopamine release across a range of stimulation frequencies and decreased $\alpha 6 \beta 2$ containing nicotinic receptor control over dopamine release. Additionally, nicotine locomotor sensitization correlated with accumbal dopamine modulation by nicotine and mecamylamine. Taken together, our study suggests that repeated exposure to nicotine blunts dopamine release in the NAc core through changes in $\alpha 6 \beta 2$ modulation of dopamine release and individual differences in the sensitivity to this outcome may predict variation in behavioral models of vulnerability to substance use disorder. 


\section{Introduction}

Smoking tobacco is the number one cause of preventable death in the United States, with 480,000 individuals dying each year from cigarette use and second-hand smoke exposure (U.S. Department of Health and Human Services, 2014). Nicotine, the main reinforcer in tobacco, is a primary reinforcer that has been shown to support self-administration, increase and sensitize locomotor activity, and drive drug-seeking behavior (Stolerman \& Shoaib, 1991; De Biasi \& Dani, 2011). Additionally, nicotine enhances the reinforcing effects and incentive motivation of stimuli that accompany tobacco use (Caggiula et al., 2009).

Nicotinic acetylcholine receptors (nAChRs) are necessary for both the primary reinforcing and reinforcement enhancing effects of nicotine. Activation of nAChRs in the nucleus accumbens or in the VTA can directly increase dopamine release in the striatum (Cachope et al., 2012; Threlfell et al., 2012) and systemic nAChR antagonism decreases nicotine self-administration (Corrigall \& Coen, 1989; DeNoble \& Mele, 2006; Yoshimura et al., 2007). In addition, NAc nAChRs modulate dopamine release in a frequency dependent manner (Zhang \& Sulzer, 2004). Dopamine neurons switch between tonic $(\sim 4-5 \mathrm{~Hz})$ and phasic (2-5 spikes at $20-100 \mathrm{~Hz}$ ) patterns of firing during the presentation of reinforcers or reward-related cues (Waelti et al., 2001; Tobler et al., 2005; Marinelli \& McCutcheon, 2014). Nicotine is thought to enhance the contrast between baseline firing and reward-related firing by decreasing dopamine release to tonic firing rates while increasing dopamine release to phasic firing patterns in the NAc (Rice \& Cragg, 2004). This is hypothesized to enhance the salience of reward-related cues and play a role in the reinforcement enhancing effects of nicotine. Further supporting this hypothesis, systemic antagonism of nAChRs decreases nicotine-induced enhancement of reinforcers, although the brain regions necessary for this effect have not yet been established (Liu et al., 2007; Palmatier et al., 2009).

Repeated exposure to nicotine upregulates nAChRs in the striatum (see Gentry \& Lukas, 2002; Penton \& Lester, 2009). Repeated nicotine also alters nAChR modulation of dopamine in the striatum. Two studies found that chronic oral nicotine self-administration in mice decreases 
electrically-stimulated dopamine release in the NAc core (Zhang et al., 2012; Exley et al., 2013). The same studies also found that oral nicotine self-administration decreased the influence of $\beta 2$ containing nAChRs (Zhang et al., 2012) and a6-containing nAChRs (Exley et al., 2013) over dopamine release in the NAc core. Repeated nicotine also decreases $\alpha 6 \beta 2 *$ receptor control over dopamine release in the NAc shell and ventral putamen of nonhuman primates (Perez et al., 2009, 2012).

Our lab has recently shown individual variation in the degree to which nAChRs modulate dopamine release in the NAc core and that this variation correlates with a behavioral measure of vulnerability to high levels of early drug intake (Siciliano et al., 2017). Dopamine release in the NAc core is necessary for the incentive motivation of cues (Saunders \& Robinson, 2012) and cueinduced drug seeking (Bossert et al., 2007; Saunders et al., 2013). Given the importance of $\mathrm{nAChRs}$ in modulating NAc dopamine release and their role in the dual-reinforcement effects of nicotine, chronic nicotine may modulate dopamine signals in a manner that drives further cueinduced drug seeking and use.

Additionally, it has been hypothesized that locomotor sensitization to nicotine is a marker of vulnerability to nicotine addiction (DiFranza \& Wellman, 2007). Given our previous work, we were also interested in whether individual differences in nicotine-induced locomotor sensitization would correlate with nicotine-induced changes in nAChR modulation of dopamine release.

To examine the effects of chronic nicotine on $\mathrm{nAChR}$ modulation of dopamine release in the NAc core, we used ex vivo fast-scan cyclic voltammetry (FSCV) to measure dopamine release in rats following seven days of nicotine exposure. Various stimulation parameters were used to model a range of dopamine neuron firing patterns. Then, non-selective and selective nAChR antagonists were used to examine whether repeated nicotine altered nAChR modulation of NAc dopamine release. We then assessed whether magnitude of locomotor sensitization following 
repeated nicotine correlated with nicotine-induced modulation of dopamine release across tonic and phasic stimulations.

\section{Materials and Methods}

\section{Animals}

Adult male Sprague-Dawley rats (325-350 grams, Harlan Sprague Dawley, Inc., Madison, WI) were maintained on a 12:12 h reverse light/dark cycle (4:00 a.m. lights off; 4:00 p.m. lights on) with food and water available ad libitum. All animals were maintained according to the National Institutes of Health guidelines in Association for Assessment and Accreditation of Laboratory Animal Care accredited facilities. The experimental protocol was approved by the Institutional Animal Care and Use Committee at Wake Forest School of Medicine.

Locomotor assessment and nicotine exposure

Rats were given at least a week to acclimate to the housing environment and light cycle prior to the start of experiments. All locomotor testing occurred during the dark/active cycle (9:00AM) to prevent sleep from contributing to variability in locomotor activity. Rats were first transferred to the dark locomotor testing room for one hour to habituate in their home cages. They were then placed in an acrylic locomotor activity chamber $(45.7 \mathrm{~cm} \times 45.7 \mathrm{~cm} \times 30.4 \mathrm{~cm})$ where their locomotor activity was monitored for 90 minutes. Rats were then subcutaneously injected on the flank with $0.9 \%$ saline solution, $0.2 \mathrm{mg} / \mathrm{kg}$ nicotine, or $0.4 \mathrm{mg} / \mathrm{kg}$ nicotine and replaced in the activity chamber for another 90 minutes. Nicotine (0.2-0.4 mg/kg, s.c.) or saline was administered for an additional six consecutive days during their active/dark cycle. On the seventh (last) day, locomotion was reassessed as on day one. Activity was recorded using Noldus ${ }^{\circledR}$ video camera system and analyzed using EthoVision XT (version 11.5).

Ex vivo fast scan cyclic voltammetry

The day after the final injection, rats were anesthetized with isoflurane and euthanized by decapitation. Brains were rapidly removed and transferred into ice-cold, pre-oxygenated $\left(95 \% \mathrm{O}_{2}\right.$ 
/ $5 \% \mathrm{CO}_{2}$ ) artificial cerebral spinal fluid (aCSF) containing (in $\mathrm{mM}$ ): $\mathrm{NaCl}(126), \mathrm{KCl}(2.5)$, monobasic $\mathrm{NaH}_{2} \mathrm{PO}_{4}$ (1.2), $\mathrm{CaCl}_{2}$ (2.4), $\mathrm{MgCl}_{2}$ (1.2), $\mathrm{NaHCO}_{3}$ (25), dextrose (D-glucose) (11), and L-ascorbic acid (0.4). Tissue was sectioned into $400 \mu \mathrm{m}$-thick coronal striatal slices with a compresstome ${ }^{\circledR}$ VF-300 vibrating microtome (Precisionary Instruments, San Jose, California). Brain slices were placed in submersion recording chambers and then perfused at $1 \mathrm{~mL} / \mathrm{min}$ at $32^{\circ} \mathrm{C}$ with oxygenated aCSF.

FSCV was used to assess dopamine release in the NAc core in rat brain slices (Figure 1A). A bipolar stimulating electrode was placed 100-150 $\mu \mathrm{M}$ from a carbon-fiber recording electrode (100-200 $\mu \mathrm{m}$ length, $7 \mu \mathrm{m}$ diameter) in the NAc core (Figure 1A). Dopamine release was initially evoked by a single electrical pulse (750 $\mu \mathrm{A}, 2 \mathrm{msec}$, monophasic) applied to the tissue every 3 minutes.

Extracellular dopamine was recorded by applying a triangular waveform from -0.4 to 1.2 $\mathrm{V}$ and back to $-0.4(\mathrm{Ag}$ vs $\mathrm{AgCl})$ at a scan rate of $400 \mathrm{~V} / \mathrm{s}$ using by a carbon fiber electrode. Voltammograms were recorded at the carbon fiber electrode every $100 \mathrm{msec}$. Once dopamine response was stable (three consecutive collections with $<10 \%$ variability), five-pulse stimulations were applied at varying burst frequencies $(5,10,20$, or $100 \mathrm{~Hz})$ to model the physiological range of dopamine neuron firing. After assessing the dopamine response to single and multi-pulse stimulations, various compounds targeting nAChRs (nicotine, 500 nM; mecamylamine [MEC], 2 $\mu \mathrm{M}$; dihydro-beta-erythroidine [DH $\beta \mathrm{E}$ ], $500 \mathrm{nM}$; $\alpha$-conotoxin MII [ $\alpha$-Ctx MII], $100 \mathrm{nM}$ ) were bath applied and dopamine response equilibrated (three collections within $10 \%$ variability) to single pulse stimulation. Separate slices from the same animal were used to test each drug independently, and the same frequency-response curves assessed under drug-free conditions were reassessed following drug application in each slice. In order to test the distinct contributions of $\alpha 6^{*}$ and non- $\alpha 6^{*}$ nAChRs, we added $\alpha$-Ctx MII and Dh $\beta E$ in a cumulative fashion, equilibrating and testing single and multi-pulse frequencies (described above) following $\alpha$-Ctx MII and then 
Dh $\beta E$. Changes in dopamine signaling between $\alpha$-Ctx MII [a selective $\alpha 6$ nAChR antagonist (Nicke et al., 2004)] alone and in combination with DHßE (a $\beta 2$ nAChR antagonist) differentiated the contribution of $\alpha 6^{*}$ and non- $\alpha 6^{*} \beta 2$-containing nAChRs. We focused on nAChRs containing $\alpha 6$ subunits due to its role in modulating dopamine release in the NAc (Wickham et al., 2013; Siciliano et al., 2017).

Demon Voltammetry and Analysis software was used to acquire and model FSCV data (Yorgason et al., 2011). Recording electrodes were calibrated by recording electrical current responses (in $\mathrm{nA}$ ) to a known concentration of dopamine ( $3 \mu \mathrm{M})$ using a flow-injection system. This was used to convert electrical current to dopamine concentration. Michaelis-Menten kinetics were used to determine maximal rate of dopamine uptake (Vmax) (Ferris et al., 2013). Statistical analysis

Single pulse dopamine release and Vmax were compared by one-way ANOVA and Tukey's multiple comparison in case of significance. Dopamine release across multiple frequency stimulations was normalized to each subject's pre-drug single pulse dopamine release. Multipulse dopamine release and locomotor activity were compared by two- or three-factor mixed design ANOVA. In the case of significant interactions, Bonferroni post-hoc comparisons were used. Percent changes in dopamine release following drug application were compared using twotailed unpaired $t$-tests or two-factor mixed design ANOVA. Locomotor sensitization was assessed using one-sample $t$-tests against no change. Pearson product-moment correlation was used to assess the relationship between nicotine locomotor sensitization and nicotine- and MEC-induced modulation of dopamine release. All statistics were performed using GraphPad Prism 7 (Graphpad Software, La Jolla, CA) or SPSS v. 24 (International Business Machine Corporation, Armonk, NY) with $\alpha \leq 0.05$. Values $>2$ standard deviations above or below the mean were considered outliers and excluded. Data are presented as mean \pm SEM. 


\section{Results}

Repeated nicotine exposure decreases dopamine release in the NAc core

We first examined whether repeated exposure to nicotine altered dopamine release in the NAc core. Rats were exposed to nicotine ( 0.2 or $0.4 \mathrm{mg} / \mathrm{kg}$, s.c.) for seven consecutive days, then ex vivo voltammetry was used to assess dopamine release in the NAc core the day after the final injection of nicotine (Fig. 1A). Repeated injections of nicotine significantly decreased the magnitude of dopamine evoked by a single pulse $\left(F_{2,45}=5.058, \mathrm{p}=0.01\right)$, with no significant difference between the doses of nicotine (Fig. 1B). Dopamine release was elicited by five pulse stimulations across the range of physiological dopamine neuron firing in order to examine dopamine signaling at frequencies that model tonic- and phasic-like firing patterns. As expected, frequency of the five pulse stimulation modulates dopamine release $\left(F_{4,184}=92.86, p<0.001\right)$, with higher frequencies increasing dopamine release. In concurrence with the single pulse dopamine release, repeated nicotine decreased dopamine release across the range of frequencies $\left(F_{2,46}=4.964, \mathrm{p}=0.011\right)$ and the decrease in dopamine release was not different between the doses of nicotine (Fig. 1C). The maximal rate of dopamine uptake ( Vmax) was not impacted by repeated exposure to nicotine $\left(F_{2,41}=0.528, p=0.594\right)$ (Fig. 1D). Given that the dose of nicotine did not differentially impact the magnitude of decrease in dopamine release, we focused only on the $0.4 \mathrm{mg} / \mathrm{kg}$ dose of nicotine in subsequent experiments.

$\alpha 6$-containing $n A C h R$ regulation of dopamine release is altered following repeated nicotine

To examine whether repeated exposure to nicotine had functional consequences on $\mathrm{nAChR}$ modulation of dopamine release in the NAc core, we assessed dopamine release across a range of frequencies following bath application of drugs that target $n A C h R s$. Reductions in dopamine release to single pulse stimulations, in particular, could be attributed to reductions in acetylcholine (ACh) facilitation of dopamine release magnitude. Striatal cholinergic interneurons (CIN) increase dopamine release in the NAc core by activating nAChRs on dopamine terminals (Cachope et al., 2012; Threlfell et al., 2012; Brimblecombe et al., 2018) and antagonism or 
desensitization of nAChRs decreases single pulse dopamine release (Rice \& Cragg, 2004). Surprisingly, a history of nicotine exposure did not alter the magnitude of decrease in dopamine release to single pulse stimulations following a desensitizing dose of nicotine $\left(t_{32}=0.098, p=\right.$ 0.922) (Fig. $2 \mathrm{~A}$ ) or MEC (a non-selective $n A C h R$ antagonist) $\left(t_{12}=0.87, p=0.401\right)$ (Fig. $\left.2 B\right)$.

We next used selective $\mathrm{nAChR}$ antagonists to examine whether $\beta 2^{*} \mathrm{nAChR}$-modulation of dopamine was altered by repeated exposure to nicotine since $\beta 2$-containing $n A C h R s$ are necessary for the reinforcing effects of nicotine and for nicotine-induced increases in NAc dopamine (Picciotto et al., 1998; Maskos et al., 2005). To determine this, we examined dopamine release following a bath application of $\mathrm{DH} \beta E$ [a $\beta 2$-selective antagonist $(500 \mathrm{nM})$ ]. A history of nicotine exposure significantly blunted the decreasing effects of $\mathrm{DH} \beta \mathrm{E}$ on single pulse dopamine release $\left(t_{26}=3.269, p=0.003\right)$ (Fig. $\left.2 C\right)$. To examine the contribution of $\alpha 6^{*}$ and non- $\alpha 6^{*} \beta 2-$ containing $\mathrm{nAChRs}$ to the changes in $\beta 2$-containing $\mathrm{nAChR}$ modulation of dopamine, we applied $\alpha$-Ctx MII [a selective $\alpha 6$ antagonist $(100 \mathrm{nM})$ ] followed by $\mathrm{DH} \beta \mathrm{E}$. Consistent with the $\mathrm{DH} \beta \mathrm{E}$ results above, saline treated animals had a significantly greater decrease of single dose dopamine release following treatment with $\alpha-C t x$ MII alone (solid bars) and $\alpha-C t x$ MII + DH $\beta E$ (main effect of group: $\left.F_{1,10}=8.358, \mathrm{p}=0.016\right)$. $\mathrm{DH} \beta \mathrm{E}$ did not significantly modulate the effect of $\alpha$-Ctx MII on dopamine release in either group (main effect of drug: $F_{1,10}=0.012, p=0.914$; interaction group*drug: $\left.F_{1,10}=1.293, \mathrm{p}=0.282\right)$.

Since nAChRs modulate dopamine release in a frequency dependent manner and the effects of cholinergic and nicotine-induced modulation of dopamine on behavior are hypothesized to be mediated by frequency-dependent gating of dopamine (Rice \& Cragg, 2004), we wanted to examine the effects of nicotine and non-selective and selective nAChR antagonists across a range of physiologically relevant frequencies in the NAc core. To determine this, we used five pulse stimulations across a range of frequencies to model tonic- and phasic-like firing patterns before and after nicotine or nAChR antagonism. As expected, nicotine modulated dopamine 
release in a frequency-dependent manner, decreasing dopamine release to single pulse and low frequency stimulation, but not to the highest frequency stimulation (interaction drug ${ }^{\star}$ frequency: $\left.F_{4,124}=15.383, \mathrm{p}<0.001\right)$. However, repeated nicotine exposure did not change nicotine-induced modulation of dopamine release (main effect of group: $F_{1,31}=0.026, p=0.874$ )(Fig. $3 \mathrm{~A}$ ). Similar to the effects of nicotine, MEC decreased single pulse and low frequency dopamine release, but did not affect high frequency dopamine release, and this modulation was not changed by a history of nicotine exposure (main effect of group: $F_{1,13}=0.001, \mathrm{p}=0.982$; interaction drug ${ }^{\star}$ frequency: $\left.F_{4,52}=5.419, \mathrm{p}=0.001\right)($ Fig. 3B)

To determine the role of $\beta 2$-containing $n A C h R s$ and isolate the role of $\alpha 6$ and non- $\alpha 6$ containing $\beta 2^{*} \mathrm{nAChRs}$ on dopamine release to tonic and phasic firing patterns, we applied $\mathrm{DH} \beta \mathrm{E}$ alone and following application of $\alpha$-Ctx MII. As with nicotine, $\mathrm{DH} \beta \mathrm{E}$ decreased dopamine to single pulse and low frequency stimulations, but not to the highest frequency stimulations (interaction drug*frequency: $\left.F_{4,104}=22.468, \mathrm{p}<0.001\right)$. Interestingly, $\mathrm{DH} \beta \mathrm{E}$ decreased dopamine release across the range of stimulation frequencies significantly more in saline treated rats than rats with repeated nicotine exposure (interaction drug*group: $F_{1,26}=7.608, p=0.011$ ) (Fig. $3 C$ ). In agreement with this effect being driven by a6-containing $\mathrm{nAChRs}$, dopamine release was significantly higher in rats with repeated nicotine exposure following $\alpha$-Ctx MII application (interaction drug ${ }^{*}$ group: $F_{1,10}=4.905, \mathrm{p}=0.05$ ) (Fig. 3D). Additionally, $\mathrm{DH} \beta \mathrm{E}$ did not significantly affect dopamine release in saline or nicotine treated rats when applied after $\alpha$-Ctx MII (main effect of drug: $\left.F_{1,8}=0.739, \mathrm{p}=0.415\right)$, although rats with repeated nicotine exposure did have higher dopamine release than saline treated rats at the two highest frequency stimulations following $\alpha$ Ctx MII and subsequent $\mathrm{DH} \beta \mathrm{E}$ (interaction group*frequency: $F_{4,32}=4.148, \mathrm{p}=0.008$ ) (Fig. $3 \mathrm{E}$ ).

The magnitude of nicotine sensitization predicts nicotine-induced modulation of striatal dopamine release at phasic firing frequencies 
Repeated exposure to nicotine increases nicotine-induced locomotion and nicotine sensitization is hypothesized to be a marker of vulnerability to nicotine addiction (DiFranza \& Wellman, 2007). Previous work from our lab has shown that nAChR modulation of dopamine release in the NAc core correlates with another model of vulnerability (high and low responders) (Siciliano et al., 2017). Because of these findings, we were interested in whether nAChR modulation of dopamine release may predict locomotor sensitization following repeated nicotine exposure. Acute nicotine and repeated saline did not affect locomotion. As expected, repeated nicotine injections increased locomotion following a nicotine injection, but did not alter baseline locomotion (interaction drug ${ }^{\star}$ time ${ }^{\star}$ day: $F_{20,1020}=4.994, p<0.001$ ) (Fig. $4 \mathrm{~A}$ ). Repeated injections of nicotine significantly increased nicotine-induced locomotion (one-sample t-test: $t_{31}=7.31, p<$ 0.001), while repeated saline did not alter locomotion following a saline injection (one sample ttest: $\left.t_{21}=0.881, \mathrm{p}=0.388\right)($ Fig. $4 \mathrm{~A})$.

There was individual variation in how much repeated nicotine sensitized nicotine-induced locomotion. We examined whether locomotor sensitization to nicotine predicted the effects of nicotine on dopamine release in the NAc core. Locomotor sensitization to nicotine did not correlate with the effects of nicotine on tonic frequency stimulation of dopamine $(5 \mathrm{~Hz}: \mathrm{r}=0.514$, $p=0.088$ ) (Fig. 4B), but did correlate with nicotine-induced modulation of dopamine following phasic firing rates $(20 \mathrm{~Hz}: r=0.632, p=0.028)$ (Fig. $4 \mathrm{C})$. In agreement with the effects of nicotine, locomotor sensitization did not correlate with MEC-induced modulation of dopamine release to tonic firing rates ( $5 \mathrm{~Hz}: r=0.488, p=0.326)$ (Fig. 4D), but did correlate with dopamine release to phasic firing stimulation (20 Hz: $r=0.87, p=0.024)$ (Fig. 4E).

\section{Discussion}

Our study demonstrates that seven consecutive days of nicotine injections in rats significantly reduced dopamine release magnitude in the NAc core following single pulse electrical stimulation and five pulse stimulations at frequencies ranging from $5 \mathrm{~Hz}$ to $100 \mathrm{~Hz}$. This reduction was observed after repeated exposure to both 0.2 and $0.4 \mathrm{mg} / \mathrm{kg}$ nicotine. The change in 
dopamine release was not associated with a change in dopamine transporter function, indicated by no change in the maximal rate of dopamine uptake (Vmax) across groups. Further examination of functional changes in $\mathrm{nAChR}$ modulation of dopamine release revealed that repeated nicotine blunted reductions in dopamine release elicited by the $\beta 2$ selective antagonist, $\mathrm{DH} \beta \mathrm{E}$, and the $\alpha 6$ selective antagonist, $\alpha$-Ctx MII. This blunted effect of selective antagonists was present across the entire range of stimulation frequencies examined. For higher frequencies, the repeated nicotine injections altered the dopamine response to nAChR antagonists from no change (saline) to a facilitation of dopamine release following $n A C h R$ blockade. Finally, repeated nicotine sensitized locomotor response to a systemic nicotine challenge. The magnitude of sensitization was predicted by the degree to which blocking nAChRs modulated dopamine release magnitude to frequencies that model phasic $(20 \mathrm{~Hz})$, but not tonic $(5 \mathrm{~Hz})$, firing of dopamine neurons.

Our results indicate that repeated nicotine administration $(0.2$ and $0.4 \mathrm{mg} / \mathrm{kg})$ decreases dopamine release during both single pulse stimulation and multiple pulse stimulations across a range of frequencies that model tonic and phasic firing of dopamine neurons. Moreover, repeated nicotine did not alter the frequency dependent nature of dopamine release magnitude. Although no previous study has assessed dopamine release following nicotine exposure using a model of repeated nicotine injections [which more closely mimics the rapid rate of nicotine delivery and pharmacokinetics seen with smoking than oral administration (Benowitz et al., 2009; Perez et al., 2012; Exley et al., 2013; Koranda et al., 2014)] or studied rats, these results are consistent with previous published reports showing decreases in dopamine release in the NAc and caudateputamen in mice following several weeks of oral nicotine treatment (Zhang et al., 2012; Exley et al., 2013) and the NAc shell and ventral putamen of squirrel monkeys following several months of oral nicotine treatment (Perez et al., 2009, 2012). Our model of seven days of repeated nicotine injections in rats produced a magnitude of dopamine reduction more similar to the effect sizes in monkeys compared to the studies in mice. Additionally, our effects were not due to differences in 
dopamine uptake through the dopamine transporter since Vmax was not changed by nicotine exposure.

We next examined the degree to which these nicotine-induced reductions in dopamine release could be attributed to reductions in acetylcholine (ACh) facilitation of dopamine release magnitude. Previous work has established that striatal cholinergic interneurons (CIN) supply abundant ACh to the NAc, which can facilitate dopamine release magnitude via nAChRs located directly on dopamine axons. Indeed, acute $\beta 2^{*}$ blockade or desensitization lowers the probability of dopamine release in response to single pulse and multiple pulse stimulations that model tonic firing of dopamine neurons (Rice \& Cragg, 2004; Zhang \& Sulzer, 2004; Zhang et al., 2009). $\alpha 6 \beta 2-$ containing $\mathrm{nAChRs}$ dominate $\mathrm{ACh}$ influence over dopamine release in the ventral striatum / NAc core, while $\alpha 5$-containing nAChRs play a larger role in the dorsal striatum (Exley et al., 2008). Thus, we hypothesized that if ACh release from CINs was blunted (or has less influence over dopamine release) in the NAc core following repeated nicotine injections, then both $\beta 2$ and $\alpha 6$ selective antagonists would be less effective at reducing dopamine release in nicotine treated rats compared to saline treated rats. Consistent with this hypothesis, both the $\beta 2$ selective antagonist, $\mathrm{DH} \beta \mathrm{E}$, and the $\alpha 6$ selective antagonist, $\alpha-\mathrm{Ctx}$ MII, were less effective at reducing dopamine release in animals treated with nicotine. The nonselective antagonist, mecamylamine, and a desensitizing dose of nicotine decreased dopamine equally in both saline and repeated nicotine groups. The difference in outcome between these nonselective (or desensitizing) compounds and the $\alpha 6 \beta 2$ selective compounds is unclear. One major difference between these classes of drugs is that the nonselective compounds also bind $\alpha 7 \mathrm{nAChRs,} \mathrm{which} \mathrm{are} \mathrm{located} \mathrm{on} \mathrm{glutamate}$ afferents in our slice preparation and could effectively reduce excitatory drive onto dopamine axons when blocked or desensitized with mecamylamine or nicotine, respectively. A reduction in excitatory drive on dopamine axons has the potential to decrease dopamine release to floor effects and mask the $\alpha 6 \beta 2^{*}$ mediated effects observed using our selective antagonists. 
Regardless, the involvement of $\alpha 6 \beta 2^{*} \mathrm{nAChRs}$ is consistent with previous voltammetric studies that showed $\alpha 6 \beta 2$-containing receptors are primarily responsible for $\mathrm{nAChR}$-evoked dopamine release in the ventral striatum. This is further supported by the fact that $\mathrm{DH} \beta \mathrm{E}$ had no effect on dopamine release magnitude when administered after $\alpha$-Ctx MII, suggesting minimal contribution from non- $\alpha 6$ containing nAChRs (Exley et al., 2008; Siciliano et al., 2017) to our nicotine treatment differences in dopamine release.

We next examined whether repeated nicotine injections sensitized locomotor response to nicotine challenge, as previously reported (see DiFranza \& Wellman, 2007), and whether the degree to which sensitized locomotor activity relates to the magnitude of nicotine's effect on NAc phasic signals in a slice. We show that a seven day regimen of once daily nicotine injections $(0.4$ $\mathrm{mg} / \mathrm{kg}$, s.c.) sensitizes locomotor activity, with nicotine treated rats more than doubling their locomotor activity after the sixth nicotine injection compared to the first. Although elevations in locomotor activity are the most robust $\leq 15$ minutes post injection, elevations are sustained through the entire session. We also found that the magnitude of nicotine-induced locomotor sensitization is not predicted by changes in tonic $(5 \mathrm{~Hz})$ stimulations following bath application of either nicotine or MEC, but did positively correlate with changes to phasic $(20 \mathrm{~Hz})$ dopamine release with both nicotine and MEC. This data is particularly interesting given our previous data that phasic, but not tonic, dopamine release magnitude following bath application of nicotine and MEC correlates with locomotor response to novelty (Siciliano et al., 2017), a strong predictor of acquisition rates for several drugs of abuse (Piazza et al., 1989; Mantsch et al., 2001; Ferris et al., 2013). Thus, nicotine modulation of NAc core phasic dopamine release correlates with two markers of vulnerability to substance use disorders: one in drug naïve animals and one following repeated drug exposure. This generality suggests that striatal nAChR modulation of NAc core dopamine (or the interaction of striatal acetylcholine and dopamine) may be a potential biomarker of vulnerability to SUD, or directly mediate SUD vulnerability. Indeed, recent work has shown 
mechanistic links between ACh signaling through nAChRs on dopamine axons and modulation of cue-induced motivation for natural rewards (Collins et al., 2019). Future studies will need to explore whether such findings extend to drug seeking.

In conclusion, we found that repeated nicotine injections blunt dopamine release equally across a range of stimulation frequencies that model both tonic and phasic firing of dopamine neurons and that repeated nicotine decreased the ability of $\alpha 6 \beta 2$-containing nAChRs to modulate dopamine release. This deficit in dopamine function may underlie, in part, increased vulnerability to nicotine use following repeated exposure to nicotine. In particular, CIN modulation of dopamine release (mediated through $\mathrm{nAChRs)}$ is thought to be essential for reward-related learning (Cragg, 2006) and dysregulation of this system may alter responses to rewards (i.e., nicotine) and rewardrelated cues in a manner that drive nicotine use disorder. We also extended our earlier work on the relationships between locomotor response to either novelty or acute nicotine and dopamine release magnitude following nicotine administration in the NAc. Indeed, we found that nicotine locomotor sensitization, a potential marker of vulnerability to nicotine dependence, correlates with nicotine and MEC modulation of phasic dopamine release. Together, these data suggest that repeated nicotine exposure alters $\mathrm{nAChR}$ control over dopamine release in the NAc core in a manner that is consistent with changes that may serve as a biomarker for vulnerability to nicotine use, or a mechanism for such vulnerability. 
bioRxiv preprint doi: https://doi.org/10.1101/646844; this version posted May 24, 2019. The copyright holder for this preprint (which was not certified by peer review) is the author/funder, who has granted bioRxiv a license to display the preprint in perpetuity. It is made available under aCC-BY-NC-ND 4.0 International license.

Funding: This work was supported by NIH grants DA031791 (R00), DA006634 (P50), AA007565 (T32), and GM102773 (K12).

Declaration of Interests: The authors report no conflicts of interest. 


\section{References}

Benowitz, N. L., J. Hukkanen and P. Jacob, 3rd. (2009). Nicotine chemistry, metabolism, kinetics and biomarkers. Handb Exp Pharmacol(192), 29-60. doi:10.1007/978-3-540-6924852

Bossert, J. M., G. C. Poles, K. A. Wihbey, E. Koya and Y. Shaham. (2007). Differential effects of blockade of dopamine D1-family receptors in nucleus accumbens core or shell on reinstatement of heroin seeking induced by contextual and discrete cues. J Neurosci, 27(46), 12655-12663. doi:10.1523/jneurosci.3926-07.2007

Brimblecombe, K. R., S. Threlfell, D. Dautan, P. Kosillo, J. Mena-Segovia and S. J. Cragg. (2018). Targeted Activation of Cholinergic Interneurons Accounts for the Modulation of Dopamine by Striatal Nicotinic Receptors. eNeuro, 5(5). doi:10.1523/eneuro.0397-17.2018

Cachope, R., Y. Mateo, B. N. Mathur, J. Irving, H. L. Wang, M. Morales, D. M. Lovinger and J. F. Cheer. (2012). Selective activation of cholinergic interneurons enhances accumbal phasic dopamine release: setting the tone for reward processing. Cell Rep, 2(1), 33-41. doi:10.1016/j.celrep.2012.05.011

Caggiula, A. R., E. C. Donny, M. I. Palmatier, X. Liu, N. Chaudhri and A. F. Sved. (2009). The role of nicotine in smoking: a dual-reinforcement model. Nebr Symp Motiv, 55, 91-109.

Collins, A. L., T. J. Aitken, I. W. Huang, C. Shieh, V. Y. Greenfield, H. G. Monbouquette, S. B. Ostlund and K. M. Wassum. (2019). Nucleus Accumbens Cholinergic Interneurons Oppose Cue-Motivated Behavior. Biol Psychiatry. doi:10.1016/j.biopsych.2019.02.014

Corrigall, W. A. and K. M. Coen. (1989). Nicotine maintains robust self-administration in rats on a limited-access schedule. Psychopharmacology (Berl), 99(4), 473-478.

Cragg, S. J. (2006). Meaningful silences: how dopamine listens to the ACh pause. Trends Neurosci, 29(3), 125-131. doi:10.1016/j.tins.2006.01.003

De Biasi, M. and J. A. Dani. (2011). Reward, addiction, withdrawal to nicotine. Annu Rev Neurosci, 34, 105-130. doi:10.1146/annurev-neuro-061010-113734

DeNoble, V. J. and P. C. Mele. (2006). Intravenous nicotine self-administration in rats: effects of mecamylamine, hexamethonium and naloxone. Psychopharmacology (Berl), 184(3-4), 266272. doi:10.1007/s00213-005-0054-z 
DiFranza, J. R. and R. J. Wellman. (2007). Sensitization to nicotine: how the animal literature might inform future human research. Nicotine Tob Res, 9(1), 9-20.

doi:10.1080/14622200601078277

Exley, R., M. A. Clements, H. Hartung, J. M. Mclntosh and S. J. Cragg. (2008). Alpha6containing nicotinic acetylcholine receptors dominate the nicotine control of dopamine neurotransmission in nucleus accumbens. Neuropsychopharmacology, 33(9), 2158-2166. doi:10.1038/sj.npp.1301617

Exley, R., M. A. Clements, H. Hartung, J. M. Mclntosh, M. Franklin, I. Bermudez and S. J. Cragg. (2013). Striatal dopamine transmission is reduced after chronic nicotine with a decrease in alpha6-nicotinic receptor control in nucleus accumbens. Eur J Neurosci, 38(7), 3036-3043. doi:10.1111/ejn.12298

Ferris, M. J., E. S. Calipari, J. R. Melchior, D. C. Roberts, R. A. Espana and S. R. Jones. (2013). Paradoxical tolerance to cocaine after initial supersensitivity in drug-use-prone animals. Eur J Neurosci, 38(4), 2628-2636. doi:10.1111/ejn.12266

Ferris, M. J., E. S. Calipari, J. T. Yorgason and S. R. Jones. (2013). Examining the complex regulation and drug-induced plasticity of dopamine release and uptake using voltammetry in brain slices. ACS Chem Neurosci, 4(5), 693-703. doi:10.1021/cn400026v

Gentry, C. L. and R. J. Lukas. (2002). Regulation of nicotinic acetylcholine receptor numbers and function by chronic nicotine exposure. Curr Drug Targets CNS Neurol Disord, 1(4), 359385.

Koranda, J. L., J. J. Cone, D. S. McGehee, M. F. Roitman, J. A. Beeler and X. Zhuang. (2014). Nicotinic receptors regulate the dynamic range of dopamine release in vivo. J Neurophysiol, 111(1), 103-111. doi:10.1152/jn.00269.2013

Liu, X., M. I. Palmatier, A. R. Caggiula, E. C. Donny and A. F. Sved. (2007). Reinforcement enhancing effect of nicotine and its attenuation by nicotinic antagonists in rats. Psychopharmacology (Berl), 194(4), 463-473. doi:10.1007/s00213-007-0863-3

Mantsch, J. R., A. Ho, S. D. Schlussman and M. J. Kreek. (2001). Predictable individual differences in the initiation of cocaine self-administration by rats under extended-access conditions are dose-dependent. Psychopharmacology (Berl), 157(1), 31-39.

Marinelli, M. and J. E. McCutcheon. (2014). Heterogeneity of dopamine neuron activity across traits and states. Neuroscience, 282, 176-197. doi:10.1016/j.neuroscience.2014.07.034 
Maskos, U., B. E. Molles, S. Pons, M. Besson, B. P. Guiard, J. P. Guilloux, A. Evrard, P. Cazala, A. Cormier, M. Mameli-Engvall, N. Dufour, I. Cloez-Tayarani, A. P. Bemelmans, J. Mallet, A. M. Gardier, V. David, P. Faure, S. Granon and J. P. Changeux. (2005). Nicotine reinforcement and cognition restored by targeted expression of nicotinic receptors. Nature, 436(7047), 103-107. doi:10.1038/nature03694

Nicke, A., S. Wonnacott and R. J. Lewis. (2004). Alpha-conotoxins as tools for the elucidation of structure and function of neuronal nicotinic acetylcholine receptor subtypes. Eur J Biochem, 271(12), 2305-2319. doi:10.1111/j.1432-1033.2004.04145.x

Palmatier, M. I., M. E. Levin, K. L. Mays, E. C. Donny, A. R. Caggiula and A. F. Sved. (2009). Bupropion and nicotine enhance responding for nondrug reinforcers via dissociable pharmacological mechanisms in rats. Psychopharmacology (Berl), 207(3), 381-390. doi:10.1007/s00213-009-1666-5

Penton, R. E. and R. A. Lester. (2009). Cellular events in nicotine addiction. Semin Cell Dev Biol, 20(4), 418-431. doi:10.1016/j.semcdb.2009.01.001

Perez, X. A., J. Ly, J. M. Mclntosh and M. Quik. (2012). Long-term nicotine exposure depresses dopamine release in nonhuman primate nucleus accumbens. J Pharmacol Exp Ther, 342(2), 335-344. doi:10.1124/jpet.112.194084

Perez, X. A., K. T. O'Leary, N. Parameswaran, J. M. Mclntosh and M. Quik. (2009). Prominent role of alpha3/alpha6beta2* nAChRs in regulating evoked dopamine release in primate putamen: effect of long-term nicotine treatment. Mol Pharmacol, 75(4), 938-946. doi:10.1124/mol.108.053801

Piazza, P. V., J. M. Deminiere, M. Le Moal and H. Simon. (1989). Factors that predict individual vulnerability to amphetamine self-administration. Science, 245(4925), 1511-1513.

Picciotto, M. R., M. Zoli, R. Rimondini, C. Lena, L. M. Marubio, E. M. Pich, K. Fuxe and J. P. Changeux. (1998). Acetylcholine receptors containing the beta2 subunit are involved in the reinforcing properties of nicotine. Nature, 391(6663), 173-177. doi:10.1038/34413

Rice, M. E. and S. J. Cragg. (2004). Nicotine amplifies reward-related dopamine signals in striatum. Nat Neurosci, 7(6), 583-584. doi:10.1038/nn1244

Saunders, B. T. and T. E. Robinson. (2012). The role of dopamine in the accumbens core in the expression of Pavlovian-conditioned responses. Eur J Neurosci, 36(4), 2521-2532. doi:10.1111/j.1460-9568.2012.08217.x 
Saunders, B. T., L. M. Yager and T. E. Robinson. (2013). Cue-evoked cocaine "craving": role of dopamine in the accumbens core. J Neurosci, 33(35), 13989-14000. doi:10.1523/jneurosci.0450-13.2013

Siciliano, C. A., J. M. McIntosh, S. R. Jones and M. J. Ferris. (2017). alpha6beta2 subunit containing nicotinic acetylcholine receptors exert opposing actions on rapid dopamine signaling in the nucleus accumbens of rats with high-versus low-response to novelty. Neuropharmacology, 126, 281-291. doi:10.1016/j.neuropharm.2017.06.028

Stolerman, I. P. and M. Shoaib. (1991). The neurobiology of tobacco addiction. Trends Pharmacol Sci, 12(12), 467-473.

Threlfell, S., T. Lalic, N. J. Platt, K. A. Jennings, K. Deisseroth and S. J. Cragg. (2012). Striatal dopamine release is triggered by synchronized activity in cholinergic interneurons. Neuron, 75(1), 58-64. doi:10.1016/j.neuron.2012.04.038

Tobler, P. N., C. D. Fiorillo and W. Schultz. (2005). Adaptive coding of reward value by dopamine neurons. Science, 307(5715), 1642-1645. doi:10.1126/science.1105370

U.S. Department of Health and Human Servies. (2014). The Health Consequences of Smoking: 50 Years of Progress. A Report of the Surgeon General. Atlanta, GA: U.S. Department of Health and Human Servise, Centers for Disease Control and Prevention, National Center for Chronic Disease Prevention and Health Promotion, Office on Smoking and Health.

Waelti, P., A. Dickinson and W. Schultz. (2001). Dopamine responses comply with basic assumptions of formal learning theory. Nature, 412(6842), 43-48. doi:10.1038/35083500

Wickham, R., W. Solecki, L. Rathbun, J. M. McIntosh and N. A. Addy. (2013). Ventral tegmental area alpha6beta2 nicotinic acetylcholine receptors modulate phasic dopamine release in the nucleus accumbens core. Psychopharmacology (Berl), 229(1), 73-82. doi:10.1007/s00213013-3082-0

Yorgason, J. T., R. A. Espana and S. R. Jones. (2011). Demon voltammetry and analysis software: analysis of cocaine-induced alterations in dopamine signaling using multiple kinetic measures. J Neurosci Methods, 202(2), 158-164. doi:10.1016/j.jneumeth.2011.03.001

Yoshimura, R. F., D. J. Hogenkamp, W. Y. Li, M. B. Tran, J. D. Belluzzi, E. R. Whittemore, F. M. Leslie and K. W. Gee. (2007). Negative allosteric modulation of nicotinic acetylcholine 
receptors blocks nicotine self-administration in rats. J Pharmacol Exp Ther, 323(3), 907-915. doi:10.1124/jpet.107.128751

Zhang, H. and D. Sulzer. (2004). Frequency-dependent modulation of dopamine release by nicotine. Nat Neurosci, 7(6), 581-582. doi:10.1038/nn1243

Zhang, L., Y. Dong, W. M. Doyon and J. A. Dani. (2012). Withdrawal from chronic nicotine exposure alters dopamine signaling dynamics in the nucleus accumbens. Biol Psychiatry, 71(3), 184-191. doi:10.1016/j.biopsych.2011.07.024

Zhang, L., W. M. Doyon, J. J. Clark, P. E. Phillips and J. A. Dani. (2009). Controls of tonic and phasic dopamine transmission in the dorsal and ventral striatum. Mol Pharmacol, 76(2), 396404. doi:10.1124/mol.109.056317 


\section{Figures and Captions}

A.

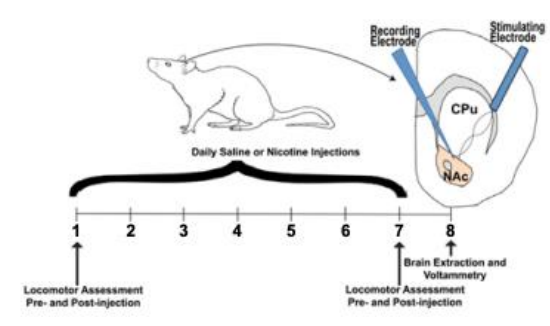

B.

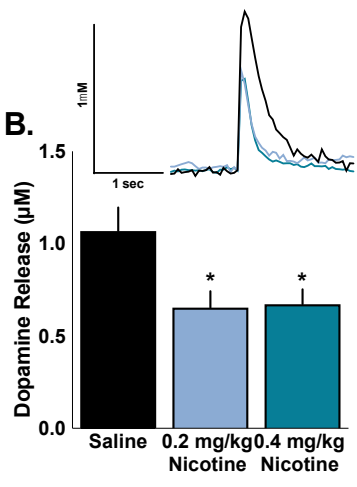

C.

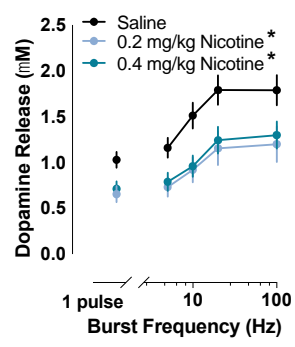

D.

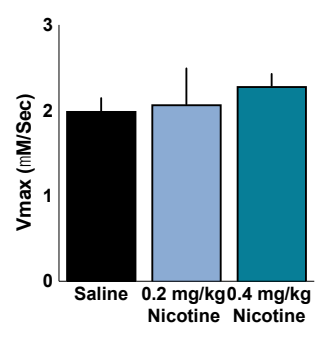

Figure 1. Chronic nicotine administration lowers dopamine signaling. (A) Experimental timeline of locomotor assessments, nicotine injections, and voltammetry. Rats were given subcutaneous injections of saline or $0.2 \mathrm{mg} / \mathrm{kg}$ or $0.4 \mathrm{mg} / \mathrm{kg}$ nicotine for seven days, with locomotor assessment on Days 1 and 7. On the eighth day, brains were extracted and ex vivo voltammetry was used to examine dopamine release in the nucleus accumbens core. (B) Chronic exposure to nicotine lowers electrically-stimulated single pulse dopamine release compared to saline. (C) Nicotine decreases both dopamine release, but does not differ between doses. (D) Maximal rate of diddopamine uptake $\left(V_{\max }\right)$ is unaffected by nicotine exposure. Bars and symbols represent means \pm SEMs, ${ }^{*} p<0.05$. 

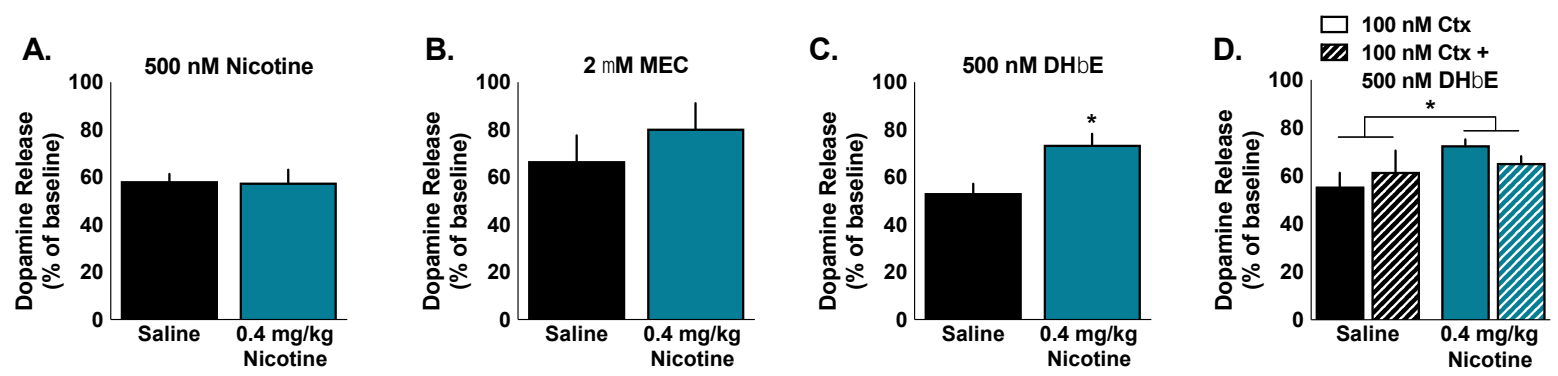

Figure 2. Chronic nicotine alters $\alpha 6 \beta 2 \mathrm{nAChR}$ modulation of single pulse dopamine. (A) Chronic nicotine exposure did not alter the effect of nicotine (500 nM) or (B) MEC [a non-selective nAChR antagonist $(2 \mu \mathrm{M})$ ] on single pulse dopamine release in the NAc core. (C) DH $\beta E$ [a selective $\beta 2 \mathrm{nAChR}$ antagonist ( $500 \mathrm{nM}$ )] decreased dopamine release significantly more in saline than nicotine treated rats. (D) Chronic nicotine exposure also blunted the decrease in single pulse dopamine release following application of $\alpha-C t x$ MII [a selective $\alpha 6 \mathrm{nAChR}$ antagonist (100 nM)] followed by DH $\beta E$. This order was used to differentiate the effect of $\alpha 6$ and non- $\alpha 6 \mathrm{nAChRs}$. Bars and symbols represent means \pm SEMs, ${ }^{*} p<0.05$. 


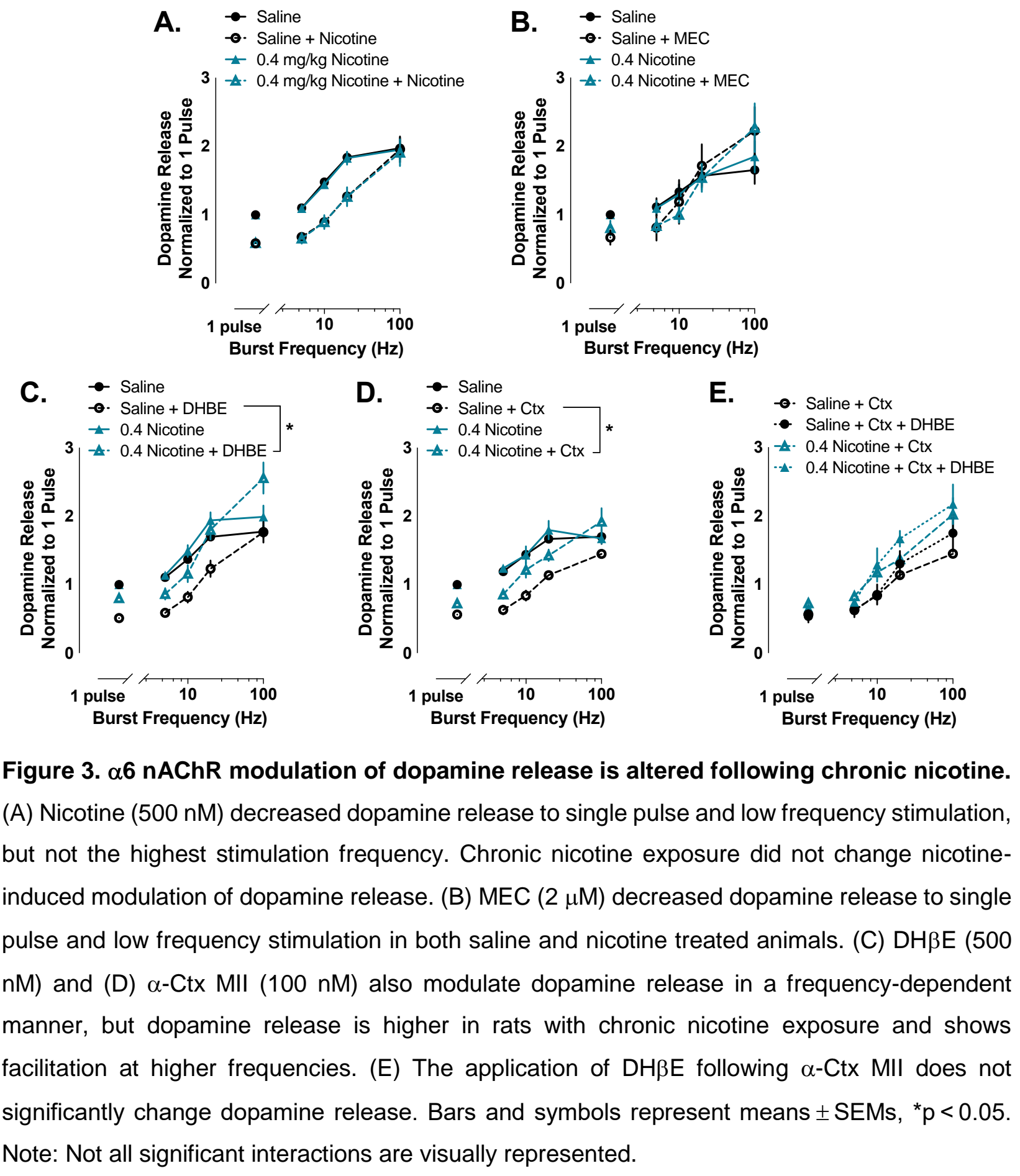



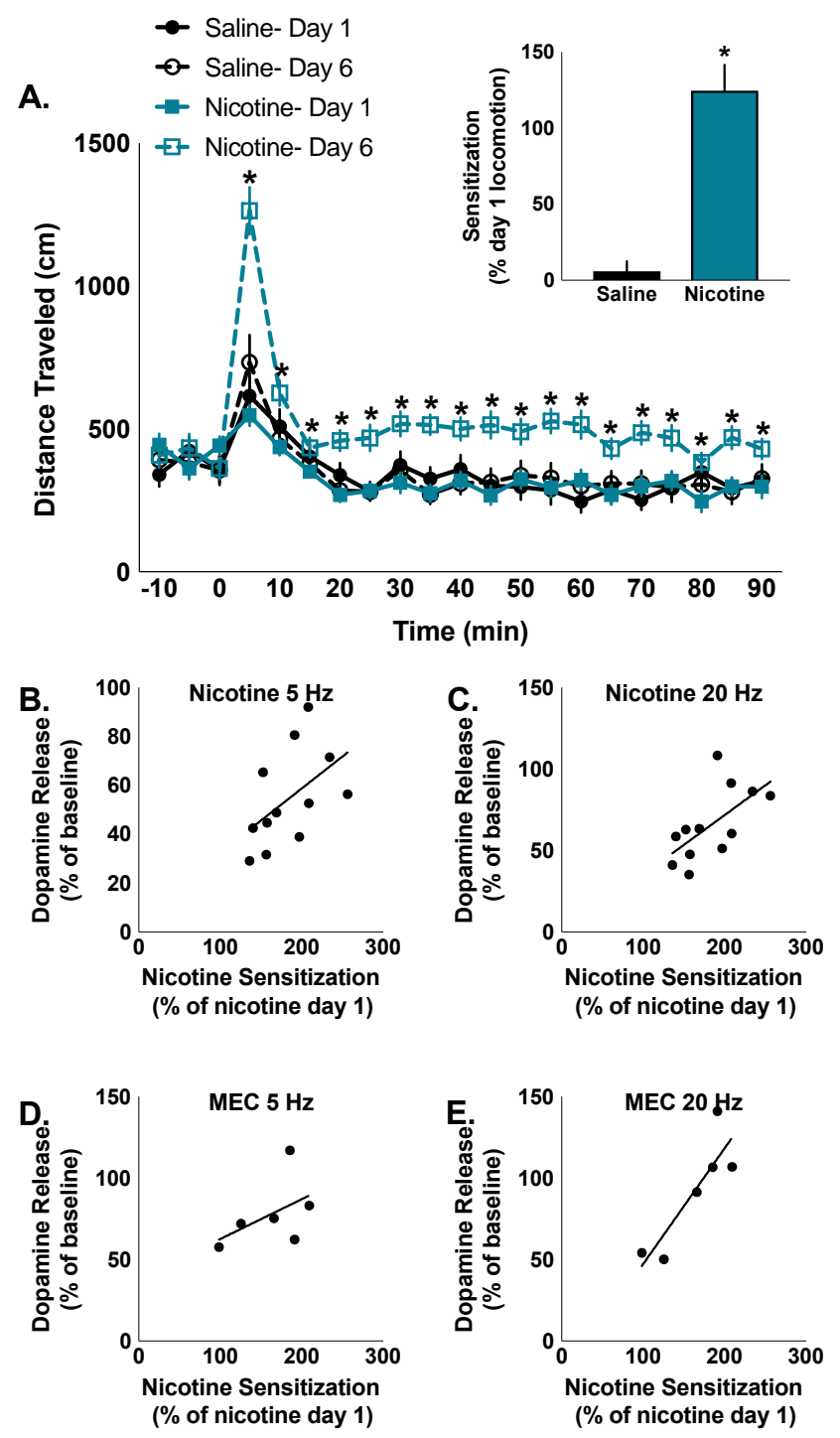

Figure 4. The magnitude of nicotine-induced sensitization predicts the effects of nicotine on dopamine release to phasic firing in the NAc. (A) Nicotine increases post-injection locomotion significantly more following repeated nicotine exposure. Repeated saline and acute nicotine do not alter locomotion. Inset: Repeated injections of nicotine significantly changed nicotine-induced locomotion, while repeated injections of saline did not change locomotion following a saline injection. (B) Magnitude of nicotine-induced locomotor sensitization is not predicted by changes in tonic $(5 \mathrm{~Hz})$ stimulations following bath application of nicotine $(500 \mathrm{nM})$, (C) but is predicted by nicotine-induced changes to dopamine release following phasic $(20 \mathrm{~Hz})$ stimulation. (D) Similarly, magnitude of nicotine locomotor sensitization was not correlated with MEC-induced $(2 \mu \mathrm{M})$ changes in dopamine release to tonic stimulation, $(E)$ but did positively correlate with changes to phasic dopamine release following MEC application. Bars and symbols represent means \pm SEMs, ${ }^{*} p<0.05$. 